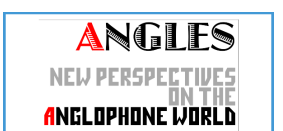

ANELOPHONE WORLD

\section{Angles}

New Perspectives on the Anglophone World

\section{$7 \mid 2018$}

Digital Subjectivities

\title{
Virtually Treatable: Temporalities and Encodings of Traumatic Experiences
}

Michael Friedman and Kathrin Friedrich

\section{Q OpenEdition \\ 1 Journals}

\section{Electronic version}

URL: https://journals.openedition.org/angles/893

DOI: 10.4000 /angles.893

ISSN: 2274-2042

\section{Publisher}

Société des Anglicistes de l'Enseignement Supérieur

\section{Electronic reference}

Michael Friedman and Kathrin Friedrich, "Virtually Treatable: Temporalities and Encodings of

Traumatic Experiences", Angles [Online], 7 | 2018, Online since 01 November 2018, connection on 06 June 2022. URL: http://journals.openedition.org/angles/893 ; DOI: https://doi.org/10.4000/angles.893

This text was automatically generated on 6 June 2022.

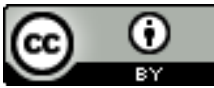

Angles est mise à disposition selon les termes de la Licence Creative Commons Attribution 4.0 International. 


\title{
Virtually Treatable: Temporalities and Encodings of Traumatic Experiences
}

\author{
Michael Friedman and Kathrin Friedrich
}

We thank Albert Rizzo for giving us the permission to use the photos of Bravemind and STRIVE.

1 Trauma - with all its different characteristics - is central to the condition of modern subjectivity and psychological temporality. ${ }^{1}$ While psychoanalysis, traditional exposition therapy and psychotherapy have developed various techniques for treating the symptoms of traumatic experiences, the use of virtual reality (VR) applications is a relatively new therapeutic concept. Digital media technologies rely on a fundamental paradox, namely the challenge of encoding and operationally interfacing both deterministic machine processes and polysemic symbolic and sensual human experiences. Hence it is not only interesting but also pertinent to explore how trauma, patients and therapeutic options are encoded within such applications that, in part, constitute and alter subjective experiences. The issue of how deterministic and aesthetic processes are related within media technologies and particularly through visual and haptic interfaces points to the crucial question of how trauma, traumatic events and hence subjective and pathological conditions are conceptualized. This not only relates to the question of how subjective experiences can be modelled on an abstract and theoretical level, it also points to the crucial issue of how the temporality of such experiences can be subsumed under a certain concept of psychological treatment, and hence transferred into therapeutic tools and practices. We therefore aim to show that digital and virtual technologies prompt a new conception of the temporality of the trauma.

With Freud's "Beyond the Pleasure Principle" (1920), one sees that the temporality of trauma poses a problem to the traditional conceptions of linear temporality and causality. Freud, with his "talking cure" techniques, emphasized that trauma is prompted retroactively. In practice, we therefore cannot know when it will erupt, what constitutes the traumatizing event - if it is even representable - or whether one can 
put a stop to its effects or to its repetition. For Freud, trauma is prompted by the repetition of a symbolic element, hence the event becomes traumatic retroactively. But this repetition is itself problematic both temporally and in terms of content, since it is not clear if it even matters what comes to be repeated or how many times it will be repeated. This is what led Freud to the formulation of the concept of an "analysis without end", stemming from the endless character of the temporality of trauma. If trauma always repeats and is un-representable, is it even treatable? This question stands at the centre of our concerns in this article, and we claim that the questions of treatment, its regulation, and the coding of trauma depend entirely on the medium that is used.

3 While for Freud trauma therapy posits a potentially never-ending experience of traumatic memories that cannot be triggered by already known inputs or stimuli, the use of virtual reality applications suggests a new therapeutic concept. They renew our conceptions of trauma, its temporality together with its symbolic yet therapeutic triggers. Two innovative medical virtual reality technologies named Bravemind and STRIVE have been developed by the University of Southern California's Institute for Creative Technologies since the early 2000s. Each offers a new conceptualization of trauma, pointing towards the emergence of a digitally treatable subject, both on a retro- and pro-active level.

Bravemind "is a clinical, interactive, VR based exposure therapy tool" (BRAVEMIND) that aims at helping soldiers cope with the symptoms caused by traumatic experiences during missions after they return home. This suggests a change in the conceptualization of trauma; its temporality is envisioned in the sense that the object of the trauma is well-known and its effects can be reduced over time. Bravemind promises to restore subjective functionality in the sense that trauma is conceptualized as controllable and hence treatable over a prolonged duration.

5 STRIVE goes one step further, proposing to encode the traumatic experience by preparing soldiers for future traumas. The software application is described as a "storydriven approach to using VR for understanding and training psychological resilience in service members prior to combat deployment. The goal is to better prepare [troops] for the emotional challenges of war, potentially reducing the later incidence of PostTraumatic Stress Disorder (PTSD)." ${ }^{2}$ This approach anticipates PTSD and pre-emptively addresses it, prior to any combat experience: resilience training for soldiers against trauma prior to deployment carries the promise of reduced indications for PTSD therapy post-mission.

6 We wish to explore the discursive and conceptual levels attached to the encoding and treatment of post-traumatic disorders in soldiers by means of virtual therapy. We will do so through the lens of the temporality involved in these methods. We will begin by clarifying the notion of trauma and the potentiality of treating it with regard to Freud's conceptions, starting with the Freudian approach, since it he who emphasized the special temporality of the trauma and its triggers and symptoms. In particular, we will clarify what is considered to be the structural and temporal "code" of trauma, its subjective disorders and related therapeutic options. By shifting the focus to applications of virtual reality exposure therapy (VRET) we will show how these applications operate in a completely different field of subjectivity, i.e. digital subjectivity. We will use the example of the VRET application Bravemind to explore how digital and human processes are conceptualized and interfaced under the paradigm of 
virtual treatment. Following this, the rather new application STRIVE provides an interesting example of how virtual reality technologies are conceptualized and employed in resilience training against possible traumatic experiences prior to military missions. We will examine marketing material and subject-specific texts to discursively analyse how subjective traumatic experiences are conceptualized both figuratively and literally as virtually treatable in advance to actual physical involvement.

\section{Freud and the Impossible Codification}

One of the first conceptions of trauma was presented by Sigmund Freud. Our main question here concerns the validity of the above-mentioned separation between the codification of triggers (i.e. what would necessarily cause the trauma to manifest itself), the trauma itself (whether it exists or not), and its symptoms (the manifestation of the trauma). One should note that if the term "trauma" clearly appears as an "entity" in discursive and historical analysis, we do not claim anything about it or about its ontological status (as an "entity" as such). We rather chose to focus on how its triggers and various symptoms are treated. We suggest Freud himself thought of trauma as unrepresentable. In order to see how the triggering of trauma and its symptoms was conceptualized by Freud, let us examine what may be called its symbolic codification as seen in the repetition compulsion (Wiederholungszwang) against what it apparently contradicts: the pleasure principle.

Until 1920, Freud's research understood dreams as an indicator of the pleasure principle. But in 1920 a conceptual twist occurred in the way he understood this principle; a turn, as we will demonstrate below, that had the same operational characteristics as the triggering of trauma itself. In his seminal 1920 paper "Beyond the Pleasure Principle," Freud concluded ex-soldiers could derive another kind of satisfaction from their nightmares. Their nightmares recreate scenes from the war, scenes that contradict the pleasure principle since they are terrifying and do not bring any pleasure. Hence, the conception of the pleasure principle reached a limit. Seeing this limit, Freud deduced that the unique satisfaction that arises from the nightmares does not differentiate between pleasure and displeasure. Freud's discovery shows that the pleasure principle becomes increasingly ambiguous and uncertain. The most disturbing example is the appearance of the phenomenon of repetition compulsion, the spectacle of a repeating trauma, which nevertheless induces some sort of pleasure.

Examining Freud's examples more closely, he seemingly focuses on extreme cases: traumatic dreams and the Fort-Da game (see below), concluding with an essential principle, being beyond the pleasure, which points towards one of the basic mechanisms of the subject. The example Freud gives of the repetition of traumatic dreams exemplifies the subject's constant repetition of the same situation of his traumatic experience: "Now dreams occurring in traumatic neuroses have the characteristic of repeatedly bringing the patient back into the situation of his accident, a situation from which he wakes up in another fright." (Freud 1920: 13) How can one explain the repetition of the same traumatic dream, when, as Freud indicates, the traumatized subject does not want to deal with the trauma in his daily life?

Another example that Freud gives to illustrate the necessary repetition of traumatic events in order to detect another principle, beyond the pleasure principle, is the Fort$\mathrm{Da}$ game of his grandson, which at first sight recreates or processes the traumatic 
experience of the abandonment of the mother. When the child throws away a wooden reel, he says "fort" ("away"), and when he pulls it back, he shouts "da" ("here"). The first explanation that Freud gives - that the child tries to take control over an unpleasant situation - is not satisfactory, since the repetition of this same scenario would not induce pleasure. However, as Freud indicates, it is the process of repetition itself that produces pleasure, not the unpleasant experience. An essential question regarding trauma arises. If it is repetition itself that prompts pleasure, does it even matter what it is repeating? Or does the content of the repeating trauma become secondary, even arbitrary, even if it remains essential? Freud's discovery suggests that the enjoyment produced cannot be signified by any element in this game, except by the compulsion to repeat.

11 Thus, according to Freud, this automatic compulsion signifies a meeting with an object that cannot be represented in reality at all: either being abandoned by the mother or encountering death. This is in fact the source for another form of pleasure: i.e. "the repetition carried along with it a yield of pleasure of another sort" (Freud 1920: 16). The repeating trauma is not meant at all to process what one might designate as the traumatic event, but rather the opposite. The repetition of the trauma is a means of creating a pleasure, which is not directed towards the ego.

What is already clear from Freud's analysis is that the repetition of the trauma is beyond the reach of the ego and the trauma itself is un-representable. ${ }^{3}$ Since knowing how trauma operates - how it is coded and regulated - holds the key to its treatment, an essential question remains: is it treatable? As was hinted above, however, and as we will show below, even if Freud did not use the code metaphor, his writing subverted the very idea that there is such a fixed codification, known in advance, either in terms of always-already-known words or images, triggering the patient.

This conception is most clearly articulated in Freud's 1937 paper "Analysis Terminable and Interminable." In this paper, he describes a case study of an unsuccessful treatment of a traumatized female patient, who "proved inaccessible to a further attempt at analysis" (Freud 1937: 222). Freud indicates that it is the repetition of the trauma that evokes and triggers the trauma itself. The traumatic event therefore originates in repetition and does not exist as such. This point is crucial and deserves emphasis: as Freud additionally describes, the woman has suffered between the first and the second event "disasters in her family, financial losses, [...] [she had no] hope of happiness in love." (Freud 1937: 222) Nothing in these former disasters triggered the (re)activation of the trauma. Only the second event substantializes and consolidates the trauma as such, although it is unclear what the traumatic event is. In other words, there is no pre-given codification to what triggers the trauma, which might guide its general treatment: what triggers a specific war event to become traumatic for a given soldier is arbitrary, and might not necessarily be a sound of explosion, but rather the smell of a specific flower or a word she/he heard. But how should one deal then with traumatic events? Should one actually repeat them in order to extract or exhaust what might trigger them? What should one actually repeat, if the trigger is not even known? Freud himself discusses these issues:

If, however, what we are aiming at is a prophylactic treatment of instinctual conflicts that are not currently active but merely potential, it will not be enough to regulate sufferings which are already present in the patient and which he cannot avoid. We should have to make up our minds to provoke fresh sufferings in him. (Freud 1937: 231-2) 
is enough to remember that when Freud discusses tension and the neuroses of children and the way to handle these phenomena, he immediately notes that the way psychoanalysis regards the education of children is not at all a prophylactic one. ${ }^{4}$ As Jacob A. Arlow points out, behind the prophylactic treatment "is the illusory, magical quest for eternal happiness and perfection" (Arlow 1991: 51). This is a key issue that will become even more critical when we will discuss STRIVE. Even though Freud distances himself from the prophylactic solution, his later proposal echoes the initial suggestion:

[t]his therefore leaves only the one method open to us - the one which was in all probability the only one originally contemplated. We tell the patient about the possibilities of other instinctual conflicts, and we arouse his expectation that such conflicts may occur in him. (Freud 1937: 233) The obvious question that arises is whether and in what way the trauma is treatable, if, following Freud, its repetition triggers it. This question indicates that the trauma, according to Freud, is in fact incurable insofar as we recall that the trauma "proved inaccessible to a further attempt at analysis." This may be seen even more clearly with another example from Freud's case studies: from the beginning of his paper on Sergei Pankejeff, better known as the Wolf Man, it is evident that the treatment itself has no end and does not end. A few years after finishing psychoanalysis with Freud, Pankejeff developed psychotic delusions and continued therapy for six decades with Freud's disciples until his death (Freud 1937: 217-8).

Following the Wolf Man case, one might say that the trauma or the traumatized subject is being transferred endlessly from one psychoanalyst to another. This is a strange "treatment" of the trauma, as if the repetition of it recreated it only in order to hand it over to yet another attempt to process it, to find out what triggered it. But the problematic issue here is the ambiguousness of the trigger itself and the indeterminacy of the number of repetitions before an event is recognized as traumatic (do two repetitions suffice? five? eleven?). ${ }^{5}$ Freud's solution to this situation is somehow unique: he suggests an artificial or arbitrary date for ending the treatment (Freud 1937: $218,222)$. This arbitrariness and artificial conclusion suggests a failure of codification, that is a failure or separation between a possible list of already known words or images that might trigger the trauma and between its actual occurrences. It is precisely due to the retroactive temporality of Freudian trauma that "static" codification, i.e. codification known in advance, fails.

Freud hence reveals that within a psychoanalytical treatment, one cannot expect a separation between the underlying, "coding" structure, which should have indicated beforehand the triggering events for the trauma and between the emergence of the trauma itself. Moreover, he indicates that the trauma itself is a never-ending process. Even the project of reaching this separation in the future, after the trauma repeats itself, reaches a deadlock. The (re)activation of the trauma becomes, in a certain sense, impossible, since no one knows what would reactivate it. These conceptions of the trauma change completely in the $21^{\text {st }}$ century, however. As we aim to show, a new understanding of what triggers trauma has emerged together with a different concept of its possible digital codification and virtual treatability. 


\section{Digital Codifications of Virtual Reality Exposure Therapy (VRET)} the treatment of post-traumatic stress disorders (PTSD) differ significantly from Freud's psychoanalytic approach; this is true at both practical and discursive levels. Nevertheless, Freud offers a starting point for the delimitation of different therapeutic understandings of how traumatic events can be conceptualized or symbolically codified, operationally triggered and eventually treated.

The so-called virtual therapy application Bravemind, short for "Battlefield Research Accelerating Virtual Environments for Military Individual Neuro Disorders," provides an innovative and promising approach to treat post-traumatic stress disorders after military missions. The Bravemind system, which consists of interconnected software and hardware parts (Figure 1), is marketed as a "clinical, interactive, VR based exposure therapy tool." (BRAVEMIND)

Figure 1: Example set-up of Bravemind session

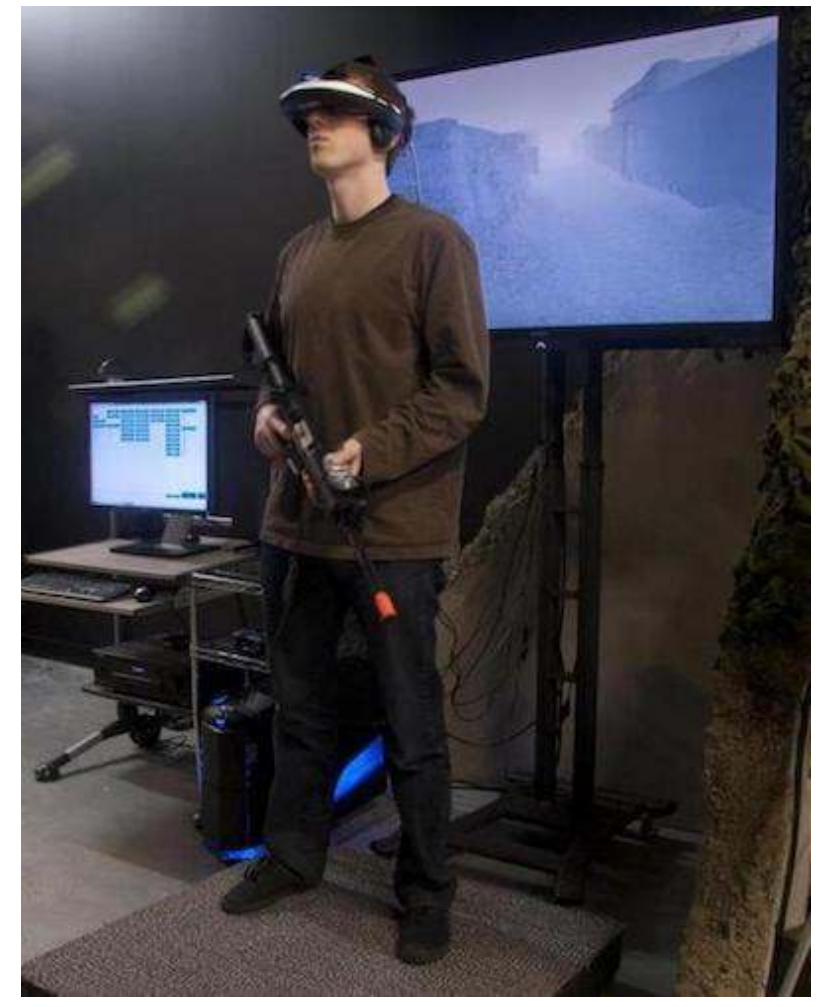

Bravemind session with a patient wearing a head-mounted display visualizing a virtual scenario and carrying a mock machine gun. On the left side one sees the computer station used by the therapist to monitor the scenario.

Source: http://uk.pcmag.com/robotics-automation-products/82227/news/how-vr-is-helping-soldierswith-ptsd. @ Skip Rizzo, USC Institute for Creative Technologies.

PTSD symptoms include difficulties to sleep, to concentrate or hyper-vigilance. ${ }^{6}$ According to the developers of Bravemind, virtual reality exposure therapy (VRET) consists in 
immersing clients in simulations of trauma-relevant environments in which the emotional intensity of the scenes can be precisely controlled by the clinician. In this fashion, VRET offers a way to circumvent the natural avoidance tendency by directly delivering multi-sensory and context-relevant cues that evoke the trauma without demanding that the patient actively try to access his/her experience through effortful memory retrieval. (Rizzo et al. 2009: 9)

Language and active memory retrieval through the talking cure stands at the core of Freud's therapeutic approach but, in this quote, the proponents of Bravemind point to a fundamental difference in therapy. The question of what is considered to be a trauma in relation to modern warfare, i.e. a trauma-related stress disorder and a treatable patient, is in large parts a question of media technology and visualization techniques. ${ }^{7}$ While Freud's conception of the talking cure and its notion of subjectivity involves mainly therapeutic techniques of narration which rely on repetitive introspection based on conversation and on language in general, virtual therapy is based on digital and visual codification of traumatic experiences by the means of virtual scenarios and the use of head-mounted displays. ${ }^{8}$ Compared to conventional psychotherapeutic and expositional therapy approaches, the developers of Bravemind stress the advantages of visual and sensual re-engagement with traumatic situations.

[...] while the efficacy of imaginal exposure has been established in multiple studies with diverse trauma populations [...], many patients are unwilling or unable to effectively visualize the traumatic event. [...] In fact, research on this aspect of PTSD treatment suggests that the inability to emotionally engage (in imagination) is a predictor for negative treatment outcomes [...]. (Rizzo et al. 2015: 257)

Virtual therapy applications force patients - who are literally unwilling to "imagine" or to talk about the traumatic situations that might have caused their stress symptoms - to accept the virtual scenario right before their eyes as a substitute for their own (lack of) imagination or for their own processing via words (see Halpern 2015). As the head-mounted display adapts the virtual scenario to his/her head movement, it mirrors the patient's focus of attention (Figure 2). 
Figure 2: Example of a virtual scenario in Bravemind

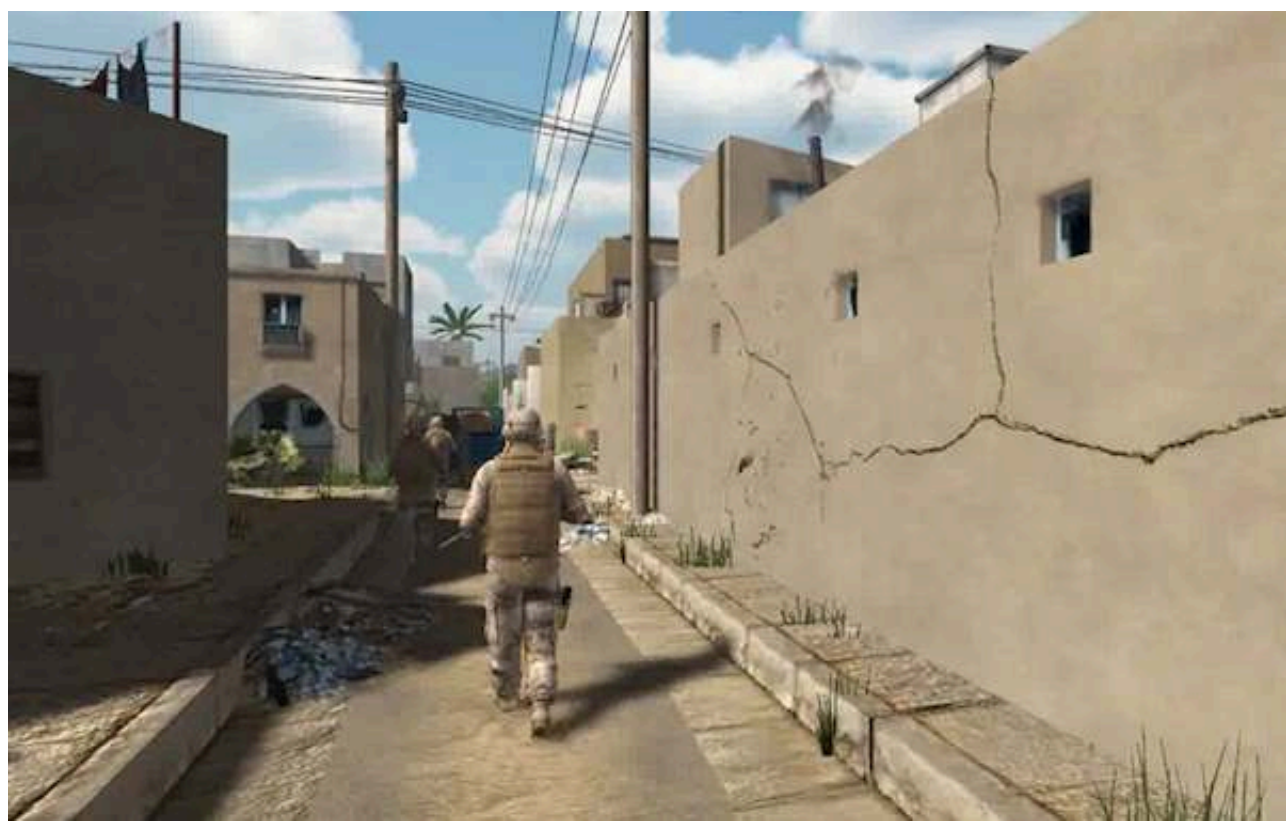

Source: http://uk.pcmag.com/robotics-automation-products/82227/news/how-vr-is-helping-soldierswith-ptsd. (c) Skip Rizzo, USC Institute for Creative Technologies.

Indeed, it can be said that in conversation with the therapist aA constant feedback loop is established in conversation with the therapist, but the temporality or rather repeatability of the virtual scenario guides the timing of the triggers, the reexperiencing and, hence, the processing of the traumatic situation. Furthermore, what is considered to be a traumatic event does not primarily rely on the narration of the patient but mostly on the available features of Bravemind.

The collective standardization of individual traumatic experiences by digital means was an integral part of the concept phase of Bravemind. As an updated version of the applications Virtual Iraq and Virtual Afghanistan, it is intended to

increase the diversity of the VR scenario content and improve the customizability of stimulus delivery to better address the needs of clinical users who have had a diverse range of trauma experiences. This effort was supported by drawing on the vast amount of user feedback generated from both clients' and clinicians' feedback from use of the previous 2007 VRE system. (Rizzo et al. 2015: 258)

The developers draw on secondary material that report the narratives provided by "returning soldiers and military subject matter experts" (Rizzo et al. 2006: 244) to identify trauma-relevant and simultaneously encodable scenarios. What patients may remember and re-imagine as being traumatic now becomes "streamlined" within a digital application. In light of the digital codification of traumatic experiences, the repetition of the trauma is only possible as it is encoded and replicated within the virtual scenarios and the capabilities of the hardware. 


\section{Preventing Traumatization by Digital Means} war-related stressful and potentially traumatic scenarios. The visual and operational design of the supposedly immersive virtual scenarios in STRIVE, as displayed on the internet through promotional videos, do not seem to differ significantly from the ones used in Bravemind. Yet STRIVE includes features that address users in a more reflective manner, by pointing their attention to the usefulness of training. Textual information and a virtual character are integrated within the scenario to incorporate "mitigation strategies on how to handle stress and develop skills on how to cope with challenging events." (STRIVE 2014) (Figure 3)

Figure 3: Avatar and textual information in STRIVE

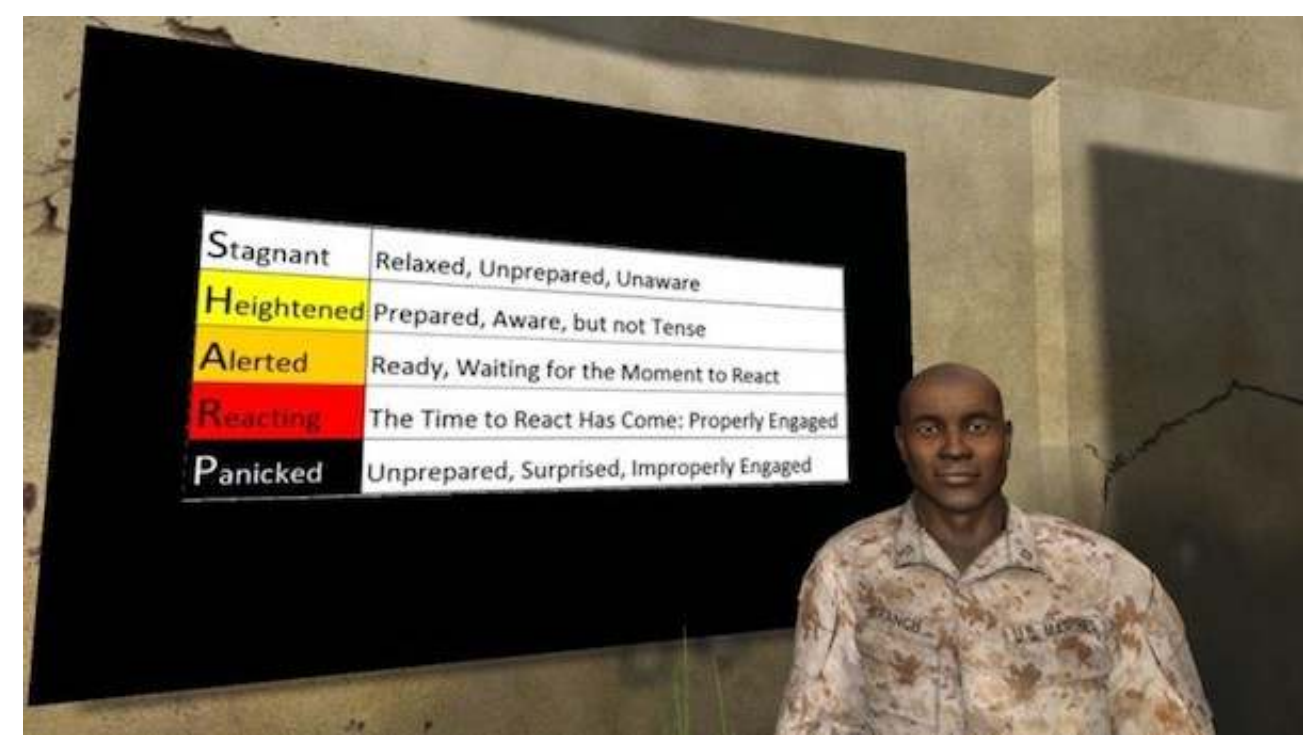

Source: STRIVE Medical Virtual Reality, https://medvr.ict.usc.edu/projects/strive/ @ Skip Rizzo, USC Institute for Creative Technologies

Interestingly, the virtual character, designed to look like a fellow US-American soldier, acts in the manner of a therapist: he instructs the user to imagine certain scenarios and tells them what the aim of the training is..$^{12}$ In this respect, the virtual figure aims to engage the user in anticipated stressful situations. Subjective involvement with 
potentially traumatic experiences is played out both on the temporal and the spatial dimensions, even if it is not clear whether these situations will actually happen in the future. What is considered to be relevant with regard to resilience training and coping skills resides merely in virtual environments. It is not verbalized in conversations with another person, i.e. the therapist who is physically present during the session. The users' in situ engagement with the virtual application and resilience training is delegated solely to the haptic and visual interfaces of the media technologies used. Depending on the handling capacity of the user, these interfaces and their basic disposition of engaging with game-like navigation techniques and the operational regimes of head-mounted display interfaces are decisive factors in this therapeutic concept.

This media file cannot be displayed. Please refer to the online document http:// journals.openedition.org/angles/893

31 From the perspective of media theory, interfaces - the theoretical concepts that guide their design, the interactions that they afford from users as well as the underlying algorithmic structures that they render visible and humanly operable - have attracted considerable critical attention. ${ }^{13}$ Media scholar Wendy Chun criticizes the fact that interfaces, in particular graphical user interfaces (GUIs),

have been celebrated as enabling user freedom through (perceived) visible and personal control on the screen. This freedom, however, depends on a profound screening: an erasure of the computer's machinations and of the history of interactive operating systems as supplementing - that is, supplanting - human intelligence. (Chun 2011: 59)

With regard to the technologically advanced and multisensory interfaces that are used for virtual therapy applications, following-up on Chun's observation, one could wonder which aspects of human intelligence are supplanted by the interfaces of STRIVE? Which deterministic codes do the visual and haptic interfaces obfuscate while at the same time addressing a specific resource of human intellect and embodied experience?

Two of the main principles that the development and application of STRIVE are associated with are stated by STRIVE's developers:

1) pre-exposure to traumatic events within a safe environment provides some degree of protection for those exposed to subsequent trauma (Latent Inhibition);

2) resilience, or the rate and effectiveness with which someone returns to normal after stress (a process termed allostasis), can be strengthened through systematic training. (STRIVE)

This quote points to an understanding of traumatic events which can be encoded and applied in a "safe environment" as well as a logic that suggests precautionary repetition as a form of effective treatment. Underlying this rationale is the assumption that traumatic events can be both anticipated and schematically repeated through "systematic training." Human subjects, in this case soldiers prior to combat missions, are viewed as active systems that can be optimized to cope with traumatic stress, preemptively enabling them to deal more effectively with related symptoms after actual exposure. Virtual technologies carry the promise to be simultaneously affective and effective. Affective in the sense they address sensual and embodied experiences and therefore evoke stress reactions. Effective in that their operational logic deterministic and repetitive - activates the therapeutic logic of this kind of stress 
resilience training that carries the promise of controlling affective reactions through interfacing humans and digital technologies. As Chun puts it: "interfaces mimic the 'desire to control', to 'govern', based on a promise of transparent technologically mediated contact." (Chun 2011: 87)

The idea of encoding potentially traumatic experiences as well as their "healing" in one digital application offers a striking example of how these virtual technologies are designed to configure a specific subjectivity that promises to be a functional and an effective part of a larger collective. ${ }^{14}$ Accordingly, the understanding of trauma and traumatic stress symptoms is both spatially and temporally restricted as it has to be adapted to the conditions that digital technology carries. The assumption that virtual therapy and training for the "immunization" against trauma could be delivered a priori hints at the basic idea that with virtual therapy the conception and codification of "trauma" is something controllable and almost calculable and certainly does not remain in an individual, subjective and "singular" sphere.

\section{Conclusion: The Temporalities of Trauma and its Triggers}

While Bravemind aims to retro-activate traumatic scenarios, STRIVE is based on the assumption that a traumatic experience will occur in the future. In this regard, the conception and application of STRIVE operates under the assumption that war-related traumatic experiences are pre-emptively known, can be digitally encoded and will be similarly, yet ultimately resiliently, experienced by soldiers. The virtual application not only provides the technological - deterministic and repetitive - infrastructure to trigger what might be traumatic, but also offers aesthetic and hence human amendable scenarios. These suggest not only the virtual rendering of simulated scenarios but also envision the virtual as potentially possible events accessible in a remote environment. Temporally, virtual resilience training operates on the basic assumption that an experience will have been traumatizing in the future and therefore needs to be addressed, trained and eased in the (virtual) present. What STRIVE offers is a renewed approach to repetition: no longer a Freudian repetition that charges retroactively an (unknown) event in the past as traumatic, but a repetition that prompts beforehand the promise of a future arrival of the traumatic.

These technological, practical and temporal virtual scenarios of STRIVE may be indeed called - following Freud's critique - prophylactic. In this sense they inversely mirror Freud's conception of triggering traumatic experiences. First, the virtual scenarios are collective ones (in the sense that all the soldiers experience the same scenarios) and their number is limited. Freud's treatment via narration of the trauma is always individual and case-dependent, which points to an infinite variety of singular, unlimited possible triggers of traumas. Second, while STRIVE points at a successful future treatment of the trauma, Freud implies that any treatment of the trauma, not to mention explicating what the trauma is, always contains a certain failure. Moreover, STRIVE already determines the temporality of the trauma beforehand - it implies knowing what the trauma potentially would be. By contrast, the Freudian traumatic event cannot be represented or codified by triggers and signifiers; it is the repetition of it that creates it as such, a repetition whose content and cycle be never determined. With Freud, it is known that something unique, individual, singular has happened, but 
no one can indicate what that something is. This stands in sharp contrast to STRIVE, which prophylactically suggests that something - collective and pre-determined - will surely happen in the future, i.e. that everyone is able to indicate the future potentiality of trauma.

\section{BIBLIOGRAPHY}

Agaibi, Christine E. and John P. Wilson. "Trauma, PTSD, and Resilience: A Review of the Literature.” Trauma, Violence, \& Abuse 6 (3) 2005: 195-216. DOI: 10.1177/1524838005277438.

Arlow, Jacob A. “A new look at Freud's “Analysis Terminable and Interminable.”' In Joseph Sandler (ed). On Freud's “Analysis Terminable and Interminable." New Haven: Yale University Press, 1991: 43-55.

Beidel, Deborah C., Christopher B. Frueh et al. "Trauma Management Therapy with VirtualReality Augmented Exposure Therapy for Combat-Related PTSD: A Randomized Controlled Trial." Journal of Anxiety Disorders, 2017: DOI 10.1016/j.janxdis.2017.08.005

Botella, Cristina et al. "Virtual Reality Exposure-based Therapy for the Treatment of Posttraumatic Stress Disorder: A Review of Its Efficacy, the Adequacy of the Treatment Protocol, and Its Acceptability." Neuropsychiatric Disease and Treatment 15, 2015: 2533-2545.

Brandt, Marisa. "Simulated War: Remediating Trauma Narratives in Military Psychotherapy." Catalyst: Feminism, Theory, Technoscience, 2 (1), 2016, http://catalystjournal.org/ojs/index.php/ catalyst/article/view/brandt/172. DOI: 10.28968/cftt.v2i1.28829.g21491

Brett T. Litz, "Resilience in the Aftermath of War Trauma: A Critical Review and Commentary." Interface Focus 6, 4(5), 2014: 1-10.

Charcot, Jean Martin, Neue Vorlesungen über die Krankheiten des Nervensystems insbesondere über Hysterie, authorized German Edition by Sigmund Freud, Leipzig, Wien: Toeplitz \& Deuticke, 1886.

Chun, Wendy Hui Kyong. Programmed Visions: Software and Memory. Cambridge: MIT Press, 2011.

Dourish, Paul. "Algorithms and their Others: Algorithmic Culture in Context." Big Data \& Society, 3(6), 2016. DOI: $10.1177 / 2053951716665128$.

Freud, Sigmund. "Repression." In Sigmund Freud. The Standard Edition of the Complete Psychological Works of Sigmund Freud, vol. XIV. Trans. James Strachey. London: Vintage Press, 1915: 143-158.

Freud, Sigmund. "Beyond the Pleasure Principle." In Sigmund Freud. The Standard Edition of the Complete Psychological Works of Sigmund Freud, vol. XVIII. Trans. James Strachey. London: Vintage Press, 1920: 7-64.

Freud, Sigmund. "New Introductory Lectures on Psycho-Analysis." In Sigmund Freud. The Standard Edition of the Complete Psychological Works of Sigmund Freud, vol. XXII. Trans. James Strachey. London: Vintage Press, 1933: 1-182.

Freud, Sigmund. “Analysis Terminable and Interminable." In Sigmund Freud. The Standard Edition of the Complete Psychological Works of Sigmund Freud, vol. XXIII. Trans. James Strachey. London: Vintage Press, 1937: 216-253. 
Friedman, Michael. "O ponavljanju in mejah formalizacije" [On Repetition and the Limits of Formalization]. Problemi, 9-10 (16), 2016: 215-234.

Halpern, Orit. "The Trauma Machine: Demos, Immersive Technologies and the Politics of Simulation." In Matteo Pasquinelli (ed). In Alleys of Your Mind: Augmented Intelligence and Its Traumas. Lüneburg: Meson Press, 2015: 53-67.

Leys, Ruth. Trauma. A Genealogy. Chicago: U. of Chicago P., 2000.

Lorenz, Daniel F. "The Diversity of Resilience: Contributions from a Social Science Perspective". Natural Hazards 67 (1), 2013: 7-24. DOI: 10.1007/s11069-010-9654-y.

Malabou, Catherine. The New Wounded: From Neurosis to Brain Damage. New York: Fordham UP, 2012.

Rizzo, Albert et al. "From Training to Toy to Treatment: A Virtual Reality Exposure Therapy Application for Iraq War Military Personnel with Post Traumatic Stress Disorder." In Michael J. Roy (ed). "Novel Approaches to the Diagnosis and Treatment of Posttraumatic Stress Disorder", Proceedings of the NATO Advanced Research Workshop on Novel Approaches to the Diagnosis and Treatment of Posttraumatic Stress Disorder, Cavtat, Croatia, 13-16 June 2005, Washington D.C.: IOS Press, 2006: 235-250.

Rizzo, Albert et al. "Development and Clinical Results from the Virtual Iraq Exposure Therapy Application for PTSD." Proceedings of the Virtual Rehabilitation International Conference, 2009: 8-15. DOI: $10.1111 / \mathrm{j} .1749-6632.2010 .05755 . \mathrm{x}$

Rizzo, Albert et al. "Virtual Reality Exposure for PTSD Due to Military Combat and Terrorist Attacks." Journal of Contemporary Psychotherapy 45(4), 2015: 255-264. DOI: 10.1007/ s10879-015-9306-3.

Smith, Roger. "Military Simulations Using Virtual Worlds." The Oxford Handbook of Virtuality. Mark Grimshaw, ed. Bolton: University of Bolton, 2013: 666-679.

\section{Websites}

BRAVEMIND. USC Institute for Creative Technologies. https://medvr.ict.usc.edu/projects/ bravemind/

STRIVE. http://ict.usc.edu/prototypes/strive/

STRIVE 2014. “VIRTUAL REALITY THERAPY: Bravemind and STRIVE.” USCICT. https:// www.youtube.com/watch?v=LRLOTzrNtVc

\section{NOTES}

1. The literature on this subject is vast, but see the following two seminal books: Leys (2000) and Malabou (2012).

2. Stress Resilience in Virtual Environments (STRIVE), USC Institute for Creative Technologies, accessed March 28, 2017, http://ict.usc.edu/prototypes/strive/ .

3. This can be seen is Freud's paper "Repression" (1915), where Freud uses the German term Vorstellungsrepräsentanz to signify that what comes in any representation or imagination of the trauma is only a substitute for it, but never the "real thing". 
4. "Prophylaxis such as this against neurotic illness, which would probably be very effective, also presupposes a quite other constitution of society. The watchword for the application of psychoanalysis to education is to be found to-day elsewhere." (Freud 1933: 149)

5. Regarding the arbitrariness of the number of repetitions, and especially as it is presented in Jacques Lacan's seminars, see: Friedman 2016.

6. According to the definition in the recent Diagnostic and Statistical Manual of Mental Disorders (DSM-5), "post-traumatic stress disorder (PTSD) involves the development of characteristic symptoms, such as distressing memories or dreams about the traumatic event, flashbacks, psychological distress produced by internal or external cues that symbolize the traumatic event, physiological reactions, avoidance of associated stimuli, and negative alterations in cognitions and mood. These symptoms appear after exposure to one or more traumatic events (e.g., exposure to war as a combatant or civilian, [...])." (Botella et al. 2015: 2533).

7. On the history of simulation and virtual technology for training purposes in military practice, see Smith (2013).

8. Nevertheless, the therapeutic set-up also contains conversations with therapists, cf. on the design and application of Bravemind from a critical perspective (Brandt 2016).

9. For a literature review on the relation of resilience in relation to trauma and post-traumatic stress disorder, see, for example: (Agaibi/Wilson 2005).

10. For a discussion of the outcomes of resilience training prior to military missions as a preventive tool, see (Litz 2014).

11. In regard to social systems, Daniel F. Lorenz discusses conceptions of resilience (Lorenz 2013). 12. The six scenarios are described by the developers of STRIVE as consisting "of a combat mission that concludes with a pivotal trauma event similar to those frequently reported by patients to be the emotional source of their post-traumatic stress ruminations. For example, witnessing the death of a child or squad member. At that moment, the virtual mentor delivers resilience training relevant to the immediate traumatic context." The visual design of these traumatic scenarios employs "advanced game development software, cinematically designed lighting/sound, and interactive narrative that maximizes credible character development and emotional engagement as well as clinical appropriateness." (STRIVE).

13. For an overview of how algorithmic processes and practices are critically investigated from different perspectives, see Dourish (2016).

14. A recent clinical study modifies the clinical effectiveness of VRET as a main therapeutical tool and concludes that "the results support the use of VRET as an efficacious treatment for combatrelated PTSD, but suggest that VRET alone does not result in optimal treatment outcomes across domains associated with PTSD." (Beidel et al. 2017)

\section{ABSTRACTS}

With Freud's groundbreaking essay "Beyond the Pleasure Principle," the temporality and treatability of trauma, its triggers and its symptoms, obtained a special status. Not only did Freud imply that trauma cannot be represented, he also eventually stated that analysis itself can never reach a definitive conclusion - analysis is an endless process, literally interminable in Freud's words. Moreover, the triggering of a trauma was arbitrary, and in no way apparent. This was due to the fact that according to Freud the trauma was triggered retroactively, regardless of when the trigger starts or stops being traumatic. On the background of this unique Freudian temporal 
retroactivity, this article constructs how new digital and virtual technologies of the $21^{\text {st }}$ century prompt a new understanding of the temporality of the trauma. While the nature of Freudian trauma is temporally unpredictable, we claim that two current virtual reality (VR) technologies used by the US military promise exactly the opposite. The first, called Bravemind, offers soldiers a way to control their experienced traumas by codifying them in virtual scenarios with visual and haptic interfaces under the paradigm of virtual treatment; the second, STRIVE, prepares solders who have not yet been deployed on the battlefield for possible future traumas. In this sense, we claim that STRIVE offers a negative mirror-reflection of the Freudian conception of trauma, and with it, a new conception of trauma itself. For Freud trauma was triggered retroactively, its ontological status was unfixed and trauma itself - its content - unrepresentable. By contrast, with STRIVE the content of trauma is known in advance, and enacted even if it is uncertain whether the anticipated traumatic event will occur.

La question de la temporalité des traumatismes, de leurs traitements, de leurs déclencheurs et de leurs symptômes figure au cœur du célèbre essai de Freud: "Au-delà du principe de plaisir". Freud ne se contente pas de suggérer que le traumatisme ne peut être représenté, il estime que l'analyse elle-même ne peut s'achever - la cure analytique est un processus sans fin, littéralement interminable dans les propres termes de Freud. De plus, l'événement déclencheur du traumatisme est arbitraire, et en rien apparent. Car pour Freud le traumatisme est déclenché rétroactivement, indépendamment $d u$ fait que le déclencheur commence ou cesse d'être traumatique. Les technologies numériques et virtuelles du $21^{\mathrm{e}}$ siècles jettent-elles une lumière nouvelle sur la temporalité du traumatisme et cette notion freudienne de rétroactivité ? Alors que la temporalité du traumatisme chez Freud est par nature imprévisible, nous soutenons que deux protocoles thérapeutiques fondés sur la réalité virtuelle et mis au point par l'armée américaine prouvent exactement le contraire. Le premier protocole de thérapie virtuelle, intitulé Bravemind, permet aux soldats de contrôler leurs expériences traumatiques passées en les encodant au sein de scénarios virtuels via des interfaces visuelles et haptiques. Le second, intitulé STRIVE, prépare des soldats qui n'ont pas encore été envoyés au combat à gérer d'éventuels traumatismes ultérieurs. En ce sens, nous estimons que STRIVE fonctionne comme le miroir inverse de la conception freudienne du traumatisme et qu'il appelle à une nouvelle approche du traumatisme. Pour Freud, le traumatisme était déclenché rétroactivement, son statut ontologique demeurait indéterminé et le contenu du traumatisme ne pouvait être représenté. En revanche, dans le cas de STRIVE, le contenu du traumatisme est connu à l'avance et mis en scène même si on n'est pas certain que l'événement traumatique que l'on anticipe aura lieu.

\section{INDEX}

Mots-clés: temporalité, traumatisme, réalité virtuelle, thérapie virtuelle, Freud Sigmund, stress post-traumatique, casques immersifs

Keywords: temporality, trauma, head-mounted displays, virtual reality, Freud Sigmund, PTSD, virtual therapy

\section{AUTHORS}

\section{MICHAEL FRIEDMAN}

Dr. Michael Friedman works as a postdoc research associate at the Cluster of Excellence "Image Knowledge Gestaltung. An Interdisciplinary Laboratory" at Humboldt University in Berlin. He 
formerly held postdoc research positions at the Institut Fourier in Grenoble and at the Max Planck Institute for Mathematics in Bonn. Contact: michael.friedman[at]hu-berlin.de

\section{KATHRIN FRIEDRICH}

Dr. des. Kathrin Friedrich works as a postdoc research associate at the Cluster of Excellence "Image Knowledge Gestaltung. An Interdisciplinary Laboratory" at Humboldt University in Berlin. Previously she was a research associate at the Academy of Media Arts in Cologne after studying media studies, law and sociology at the University of Marburg. Contact:

kathrin.friedrich[at]hu-berlin.de 